\title{
Correlation of BMI with Associated Comorbidity - A Cross Sectional Study at a Tertiary Care Centre
}

\author{
Pratibha Singh ${ }^{1}$, Yashodhara Pradeep ${ }^{2}$ \\ 1, 2 Department of Obstetrics and Gynaecology, RMLIMS, Lucknow, Uttar Pradesh, India.
}

\section{ABSTRACT}

\section{BACKGROUND}

The prevalence of overweight and obesity has increased overnutrition, under nutrition and epidemiological transition are at pace in various states of India. The recent National Family Health Survey 4 (NFHS-2015-16) data shows commendable rise in prevalence of overweight and obesity in India. We wanted to determine the prevalence of overweight and obesity in women, and evaluate the association of BMI with non-communicable diseases, and BMI with gynaecological problems.

\section{METHODS}

This is a cross sectional study conducted among 5000 female patients attending GOPD at Dr. RMLIMS, Lucknow. A total of 1999 eligible patients was stratified by BMI categories based on most recent weight and height recorded and relationship between patient characteristics and BMI categories was done. EHR. BMI calculation were determined using the most recent weight and median of all recorded heights. Relationship between patient's characteristics and BMI was tested using univariate analysis where $\chi^{2}$ was used for testing the association between weight classification and categorical characteristics. The non-parametric Kruskal-Wallis test was used for continuous characteristics.

\section{RESULTS}

1999 women with a recorded BMI were identified. There were 737 (36.87\%) patients who met the criteria of overweight (BMI 25-29.9), 233 (11.66\%) had obesity class I (BMI 30 - 34.9), 88 (4.4\%) had obesity class II (BMI>35) and 866 (43.32\%) were of normal BMI (18-24.9). There was high prevalence of diabetes and hypertension ( $P$ value $<0.0001$ ) in overweight and obese group within higher BMI compared to lower BMI categories. Clinical symptoms such as irregularity in periods, pain abdomen, infertility, PCOD are more common in overweight categories than in normal BMI category.

\section{CONCLUSIONS}

Results of this report highlight the reality of obesity prevalence and associated comorbidities. Yet despite the high prevalence, under-diagnosis continues to be a significant problem. More than $50 \%$ of the study population had BMI consistent with overweight or obesity. This cross-sectional study was designed to evaluate the scope of the problem and doing so has raised additional questions worthy of pursuit.

\section{KEY WORDS}

Lifestyle Modification, Non-Communicable Diseases, Gynaecological Symptoms, Balanced Diet Women
Corresponding Author: Dr. Yashodhara Pradeep, Head of Department,

Dr. Ram Manohar Lohia Institute of Medical Sciences, Vibhuti Khand, Gomti Nagar, Lucknow-226010, Uttar Pradesh, India. E-mail: yashodhara27@gmail.com

DOI: $10.14260 /$ jemds/2020/777

How to Cite This Article:

Singh P, Pradeep Y. Correlation of BMI with associated comorbidity- a cross sectional study at a tertiary care centre. J. Evolution Med. Dent. Sci. 2020;9(47):3543-3546, DOI: $10.14260 /$ jemds/2020/777

Submission 03-02-2020,

Peer Review 07-10-2020,

Acceptance 12-10-2020,

Published 23-11-2020.

Copyright (C) 2020 JEMDS. This is an open access article distributed under Creative Commons Attribution License [Attribution 4.0 International (CC BY 4.0)] 


\section{BACKGROUND}

Worldwide, the prevalence of overweight and obesity has more than doubled since 1980, which reached 1.9 billion overweight and 600 million obese adults in 2014. It is an estimation of WHO. It is predicted that around two thirds of global burden of disease will be accredited to chronic noncommunicable diseases, most of them strongly associated with diet.(1) In India NFHS survey 4 (NFHS 2015-16) data shows communicable rise in prevalence of overweight and obesity. Developing countries experienced more dramatic rise in the prevalence of obesity in recent decades.(2) The problem of overweight obesity increasing in country were hunger is still endemic. WHO 2006 also detected that there was high risk of high B. P, Type $2 \mathrm{DM}$ at an earlier age among people who are undernourished in younger age and obese in adulthood.(3) In last two decades the magnitude of dual nutrition burden, demographic and epidemiological transition in various states of India. Overweight and obesity are fifth leading risk of global deaths, that affect virtually all age and socioeconomic groups and threatens both developing and developed countries. Prevalence of obesity varies according to age, sex and region. In India the percentage of married women aged 15-49 who are overweight or obese increased from $11 \%$ in NFHS -2 to $15 \%$ in NFHS-3.

The primary objective of this study to determine true prevalence of overweight, obesity and related comorbidities among women aged 19-60 yrs., attending OPD of OBGYN Department at Dr. RMLIMS, Lucknow. Ethical issue: Strength \& limitation: 1) Analysis included a large sample size with recorded BMI values. 2) The electronic health records used for the study (Dr. RMLIMS, Lucknow) provide a rich source of demographic, clinical, laboratory and prescription data on patients. 3) Overweight and obesity categorization based on actual BMI calculation not International Classification of Disease Coding. 4) Limitation of this study is all subject were individual seeking Health care services, thus possibly not representative of broader Indian population. 5) Another potential limitation is all patient were identified from a single institution EHR.

\section{METHODS}

This is a cross sectional study of 1999 women conducted over a period of one year from November 2018 to November 2019. Height, weight, and BMI of all subjects who attended Dr. RMLIMS OPD. BMI Chart was used to calculate BMI. Detailed history of patients was noted. Investigations done included CBC, blood sugar, urine $\mathrm{r} / \mathrm{m}$, lipid profile, KFT, LFT, TSH, T3, T4, anti TPO antibodies. Eligible patients were stratified by BMI categories based on most recent weight and height recorded and relationship between patient characteristics and BMI categories was done. EHR includes patient demography, social, medical history, vital signs, pathology reports and diagnosis from OPD records.

\section{Inclusion Criteria}

Patient age $\geq 18$ yrs., of age (as they may not have reached their full height by $18 \mathrm{yrs}$. of age.

\section{Exclusion Criteria}

1. Patient with median height $<4^{\prime} 6^{\prime \prime}$ or $7^{\prime} 6^{\prime \prime}$, weight $>100 \mathrm{Kg}$.

2. Pregnant or having recently given birth.

3. Subjects with known hyper- or hypo-thyroidism

4. Heart failure

5. Radiation or chemotherapy treatment

6. Metastatic cancer.

A total of 1999 active patients with a recorded BMI were identified to meet the inclusion and exclusion criteria (Figure 1).

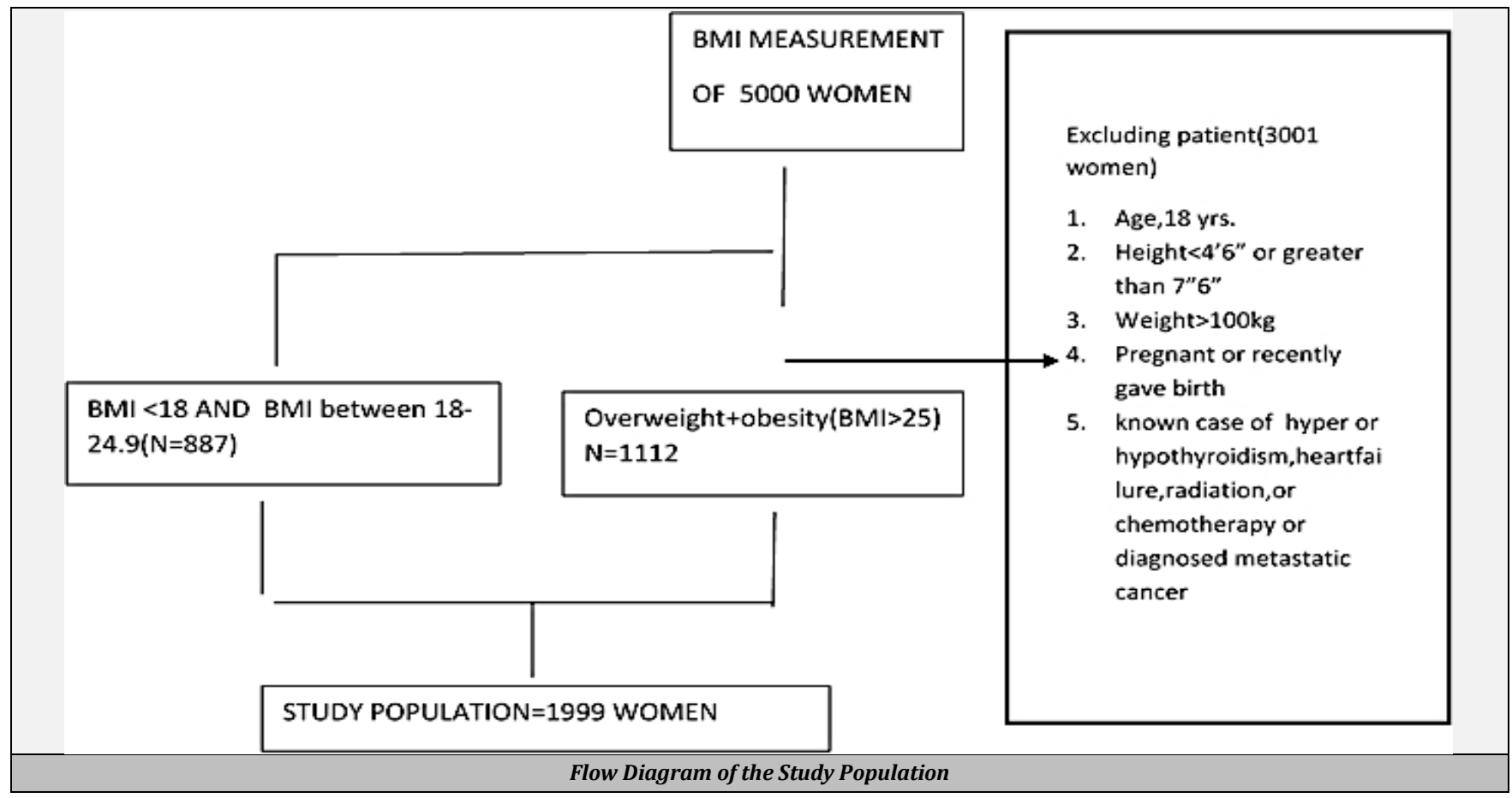




\section{Statistical Analysis}

BMI was determined using the most recent weight and median of all recorded height. The weight recorded closest to the index date was recorded as the study weight, symptoms, diagnosis, laboratory and vital signs data were recorded based on the recent values available in EHR. Comorbidity were identified in EHR any time up the index date. Relationship between patient's characteristics and weight classification (BMI categories) were tested using univariate analysis where $\chi^{2}$ was used for testing the association between weight classification and categorical characteristics. The non-parametric Kruskal Wallis test was used for continuous characteristics.

\section{RESULTS}

\begin{tabular}{|c|c|c|c|c|c|c|}
\hline \multirow[b]{2}{*}{ Age Groups } & \multicolumn{5}{|c|}{ BMI Groups } & \multirow[b]{2}{*}{ Total } \\
\hline & $<18$ & $\begin{array}{c}18 \\
\text { to } \\
24.9\end{array}$ & $\begin{array}{c}25 \\
\text { to } \\
29.9\end{array}$ & $\begin{array}{c}30 \\
\text { to } \\
34.9\end{array}$ & $>35$ & \\
\hline $18-20$ yrs. & 4 & 42 & 8 & 1 & 2 & 57 \\
\hline $21-30$ yrs. & 45 & 399 & 250 & 64 & 32 & 790 \\
\hline $31-40$ yrs. & 18 & 277 & 254 & 82 & 29 & 660 \\
\hline $41-50$ yrs. & 4 & 86 & 161 & 58 & 8 & 317 \\
\hline $51-60$ yrs. & 3 & 28 & 44 & 14 & 10 & 99 \\
\hline$>60$ yrs. & 1 & 34 & 20 & 14 & 7 & 76 \\
\hline Total & 75 & 866 & 737 & 233 & 88 & 1999 \\
\hline \multicolumn{7}{|c|}{ Table 1. Correlation of BMI with Age } \\
\hline
\end{tabular}

\begin{tabular}{|c|c|c|c|}
\hline \multirow{2}{*}{ BMI Group } & \multicolumn{2}{|c|}{ Hypertension } & \multirow{2}{*}{ Total } \\
\hline & Present & Absent & \\
\hline$>18$ & 7 & 83 & 90 \\
\hline $18-24.9$ & 45 & 814 & 859 \\
\hline $25-29.9$ & 100 & 628 & 728 \\
\hline $30-24.9$ & 58 & 175 & $233(11.66)$ \\
\hline$>35$ & 25 & 64 & $89(4.45)$ \\
\hline Total & 235 & 1764 & $1999(100)$ \\
\hline \multicolumn{4}{|c|}{ Table 2. Correlation of BMI with Hypertension } \\
\hline
\end{tabular}

\begin{tabular}{|c|c|c|c|}
\hline \multirow{2}{*}{ BMI Group } & \multicolumn{2}{|c|}{ DM } & \multirow{2}{*}{ Total } \\
\hline & Absent & Present & \\
\hline$>18$ & 90 & 0 & 90 \\
\hline $18-24.9$ & 842 & 17 & 859 \\
\hline $25-29.9$ & 697 & 31 & 728 \\
\hline $30-24.9$ & 217 & 16 & 233 \\
\hline$>35$ & 78 (87.64) & $11(12.35)$ & $89(4.45)$ \\
\hline Total & $1924(96.24)$ & $75(3.75)$ & $1999(100)$ \\
\hline \multicolumn{4}{|c|}{ Table 3. Correlation of BMI with Diabetes Mellitus } \\
\hline
\end{tabular}

\begin{tabular}{|c|c|c|c|c|c|c|c|}
\hline \multirow[b]{2}{*}{$\begin{array}{l}\text { Gynaecological } \\
\text { Complains }\end{array}$} & \multicolumn{5}{|c|}{ BMI Groups } & \multirow[b]{2}{*}{ Total } & \multirow[b]{2}{*}{$\begin{array}{c}\text { Total } \\
\%\end{array}$} \\
\hline & $\begin{array}{c}< \\
18\end{array}$ & $\begin{array}{c}18 \\
\text { to } \\
24.9\end{array}$ & $\begin{array}{c}25 \\
\text { to } \\
29.9\end{array}$ & $\begin{array}{c}30 \\
\text { to } \\
34.9\end{array}$ & $>35$ & & \\
\hline $\begin{array}{l}\text { Pain abdomen and } \\
\text { backache }\end{array}$ & 26 & 264 & 209 & 69 & 25 & 593 & 29.66 \\
\hline Breast complains & 2 & 8 & 11 & 1 & 0 & 22 & 1.10 \\
\hline CA breast & 0 & 0 & 0 & 1 & 0 & 1 & 0.05 \\
\hline CA endometrium & 0 & 2 & 1 & 0 & 0 & 3 & 0.15 \\
\hline Cancer cervix & 0 & 5 & 4 & 2 & 0 & 11 & 0.55 \\
\hline Fibroid uterus & 2 & 13 & 10 & 9 & 6 & 40 & 2.00 \\
\hline Infertility & 12 & 102 & 96 & 28 & 9 & 247 & 12.36 \\
\hline Irregular period & 26 & 261 & 229 & 67 & 28 & 611 & 30.57 \\
\hline Ovarian cyst & 1 & 11 & 11 & 3 & 1 & 27 & 1.35 \\
\hline PCOD & 5 & 33 & 28 & 8 & 0 & 74 & 3.70 \\
\hline PID & 0 & 5 & 4 & 2 & 0 & 11 & 0.55 \\
\hline $\begin{array}{l}\text { Post-menopausal } \\
\text { symptoms/bleeding }\end{array}$ & 3 & 17 & 10 & 4 & 2 & 36 & 1.80 \\
\hline Urinary complaint & 1 & 19 & 20 & 9 & 4 & 53 & 2.65 \\
\hline UV prolapse & 1 & 17 & 16 & 7 & 4 & 45 & 2.25 \\
\hline WDPV & 11 & 90 & 73 & 22 & 10 & 206 & 10.31 \\
\hline Other complains & 0 & 12 & 6 & 1 & 0 & 19 & 0.95 \\
\hline Total & 90 & 859 & 728 & 233 & 89 & 1999 & 100.00 \\
\hline
\end{tabular}

Out of 5000 women attended GOPD at Dr. RMLIMS, Lucknow between periods of November 2018-19 in EHR, after exclusion only 1999 eligible women included in the study. There were $737(36.87 \%)$ patient met the criteria of overweight (BMI 25-29.9), 233 (11.66\%) had obesity class I (BMI 30 - 34.9), 88 (4.4\%) had obesity class II (BMI>35) and $866(43.32 \%)$. that of normal BMI (18-24.9). The prevalence of overweight was $161(50.79 \%)$ is in perimenopausal women out of 317 women age 40-50 yrs. than that of age group 30-40 yrs. i.e. 254 (38.48\%) out total 660 women and $44(44.44 \%)$ out of total 99 women in age 50-60 yrs. The prevalence of hypertension in overweight group i.e. $5 \%$ out of $36.42 \%$ of overweight patients, than that of normal BMI $2.25 \%$ out of $42.97 \%$ of normal BMI (18-24.9) which is statistically significant. ( $\mathrm{p}$ value-<.000). There was high prevalence of diabetes $75(3.75 \%)$ in women and most of them belongs to overweight $31(4.25 \%)$, class $1-16(6.86 \%)$ and class 2 obesity $11(12.35 \%)$ than that of normal BMI (18-24.9) $17(1.97 \%)$ women having diabetes which is statistically significant. ( $p$ value <.000). Gynaecological symptoms such as irregular period was present in 611 (30.57\%) patients, out of that 229 $(37.47 \%)$ were overweight, $67(10.9 \%)$ were of class 1 obesity, $28(4.58 \%)$ had class 2 obesity while that of normal BMI were $261(42.71 \%)$

Maximum patient presented with complain of backache and pain abdomen 593 (29.66\%), among that 209 (35.2\%) were overweight, 69 (11.63\%), 25 (4.21\%) had class 1 \& 2 obesity respectively. Among the 247 (12.36\%) patient of infertility, 96 (38.66\%) were overweight, 28 (11.3\%) fell in class 1 obesity, 9 (3.6\%) class 2 obesity and 102 (41.2\%) having normal BMI (18-24.9). 74 Patient presented with complain of PCOD, 28 (37.83\%) were overweight, 8 patient had class 1 obesity, 33 (44.4\%) patient had normal BMI. More than $50 \%$ of patient presented with complain of $\mathrm{PMB} /$ symptoms belong to overweight and obesity.

\section{DISCUSSION}

In this extensive epidemiological analysis from Dr. RMLIMS, Lucknow, BMI value of 777 (38.6\%) women fell within categories of overweight $(21.9 \%)$, obesity class-1 (9.8\%) and class-2 (6.9\%). Thus, the prevalence of overweight/obesity is more than $50 \%$ (1112 patients) in this study population of 1999 women. This study indicate that overweight and obesity has become substantial problems among different socioeconomic spectrum of women in India, particularly in older age groups, people living in urban areas, well-educated and among household of highest wealth quintile and simultaneously among people living in poorer wealth quintile, uneducated and people belonging to low socioeconomically less developed states. The age has significant effect on obesity as it effect health according to the timing of beginning.(4) Study conducted at Cleveland clinic by Kevin M Pentalone et al found BMI value of for almost $80 \%$ of patient fell within categories of overweight (37.4\%) or obesity (41.5\%). Thus overweight and obesity posing a growing threat to people of India like western world both in in urban and rural areas as with increasing industrialization, the standard of living also rise which result in weight gain.(5) The rapid rise in prevalence of obesity can be credited to the use of mechanical transport, availability of ready to eat \& fast food, modern ways of entertainment like smart phones, Television, adoption of sedentary lifestyles \& intake of more energy dense diet. $(6,7,8)$ Identifying obesity is the first step leading to optimal interdisciplinary intervention 
ideally involving lifestyle modifications relating to nutrition and physical activity, as well as medications where necessary to reduce appetite.(9)

Therefore, while interpreting the overall prevalence of overweight \& obesity and its associated co-morbidities (hypertension, diabetes, menstrual irregularities, infertility, PCOD, backache, pain abdomen) among women require extra cautiousness in the context of wide disparities with respect to diet, physical activity \& lifestyle modification in women of India.

\section{CONCLUSIONS}

Despite the high prevalence, under diagnosis continues to be a significant problem. More than $50 \%$ of the study population had BMI consistent with overweight or obesity. Comorbidities such as diabetes, hypertension, menstrual irregularities, infertility, pain abdomen, backache are more common in overweight and obese women. This cross-sectional study was designed to evaluate the scope of the problem and in doing so has raised additional questions worthy of pursuit.

Further analysis and research will be needed to fully decipher the likely factors which affect the medical underrecognition of obesity. Under diagnosis and failure to recognise obesity as a treatable chronic disease with serious health consequences is an important barrier to effective management. Over the coming years, we anticipate continued improvement in documentation of obesity due to increasing therapy coverage by insurance companies, existing reimbursement incentives through centers of Medicare and Medicaid services and the effective use of obesity related HER functions.

Data sharing statement provided by the authors is available with the full text of this article at jemds.com.

Financial or other competing interests: None.

Disclosure forms provided by the authors are available with the full text of this article at jemds.com.

\section{REFERENCES}

[1] World Health Organisation. WHO Study on global ageing and adult health (SAGE). Geneva: WHO. 2008: p. 01.

[2] Popkin BM, Gordon-Larsen P. The nutrition transition: worldwide obesity dynamics and their determinants. International Journal of Obesity Relat Metab Disord 2004;28(Suppl 3):S2-S9.

[3] World Health Organisation, Obesity and overweight, Report of WHO Consultation on Obesity, WHO Geneva, 2006: p. 01.

[4] Ferraro KF, Kelly-Moore JA. Cumulative disadvantage and health: long-term consequences of obesity? American Sociological Review 2003;68(5):707-729.

[5] World Health Organisation. Obesity: preventing and managing global epidemic. Geneva, WHO Technical Report Series. 2000;894:04.

[6] World Health Organisation. Diet nutrition and prevention of chronic diseases. Geneva, WHO Technical Series. 2003;916:p.04.

[7] Bell CA, Adair LS, Popkin BM. Ethnic Differentiation in association between body mass index and hypertension. American Journal of Epideomology 2002;155(4);346-53.

[8] Singhal N, Misra A, Shah P, et al. Effect of controlled school based multi-component model of nutrition and lifestyle interventions on behavior modification, anthropometry and metabolic risk profile of urban Asian Indian adolescents in North India. Europian Journal of Clinical Nutrition 2010;64(4):364-73.

[9] Pantalone KM, Hobbs TM, Chagin KM, et al. Prevalence and recognition of obesity and its associated comorbidities: Cross-sectional analysis of electronic health record data from US integrated health system. BMJ open 2017;7(11):e017583. 